\title{
Determinants of Success of Businesses of Female Entrepreneurs in Taiwan
}

\author{
Lisa-Marie Schröder ${ }^{1}$, Vito Bobek ${ }^{1, *(\mathbb{D})}$ and Tatjana Horvat ${ }^{2}$ \\ 1 Institute of International Management, University of Applied Sciences FH Joanneum, 8020 Graz, Austria; \\ lisa-marie.schroeder@edu.fh-joanneum.at \\ 2 Faculty of Management, University of Primorska, 6000 Koper, Slovenia; tatjana.horvat@fm-kp.si \\ * Correspondence: vito.bobek@fh-joanneum.at; Tel.: +386-41-735-448
}

check for updates

Citation: Schröder, L.-M.; Bobek, V.; Horvat, T. Determinants of Success of Businesses of Female Entrepreneurs in Taiwan. Sustainability 2021, 13, 4842. https://doi.org/10.3390/su13094842

Academic Editors: Marc A. Rosen,

Rebeka Kovačič Lukman and

Damjan Krajnc

Received: 8 February 2021

Accepted: 8 April 2021

Published: 26 April 2021

Publisher's Note: MDPI stays neutral with regard to jurisdictional claims in published maps and institutional affiliations.

Copyright: (c) 2021 by the authors. Licensee MDPI, Basel, Switzerland. This article is an open access article distributed under the terms and conditions of the Creative Commons Attribution (CC BY) license (https:// creativecommons.org/licenses/by/ $4.0 /)$.

\begin{abstract}
This paper deals with the topic area "female entrepreneurship," and the research focuses on the determinants of female entrepreneurs' business success and sustainability, together with their impact on Taiwan's economic development. According to the Morgan Stanley Capital International (MSCI) and the Financial Times Stock Exchange (FTSE) classification, Taiwan can be considered an emerging economy. Various liberal and social theories and Hofstede's cultural dimensions were analyzed to develop some hypotheses, including some relevant success factors connected to female entrepreneurship in Taiwan. The Global Entrepreneurship Monitor (GEM) and the Female Entrepreneurship Index (FEI) were relevant for the data analysis because the research was based on secondary data with 1098 observations, and a logistic regression model was performed. The factors of fear of failure and personal network correlated significantly to female entrepreneurs' business success in Taiwan and the level of education had no significant correlation. Further research is recommended to include additional factors to achieve a higher accuracy of the model. A comparison of Taiwan with another region/country might also deliver some interesting insights.
\end{abstract}

Keywords: entrepreneurship; Global Entrepreneurship Monitor; female; Taiwan; logistic regression model; business success

\section{Introduction}

Around the globe, it is still the case that fewer women than men are becoming entrepreneurs [1,2]. The gender gap is $14 \%$ in low-income economies, and in the middle- and high-income regions/countries, the ratio shows with $26 \%$ a much higher gap [3]. Several reasons for the gap are covered in the literature, like socioeconomic characteristics, fewer years of experience, cultural background, and discrimination issues [4,5]. Concerning established businesses, which run more than 42 months, 6.2\% of female entrepreneurs own such businesses and $9.5 \%$ of male entrepreneurs from a global view. The higher the national income in a region/country, the higher the gender gap in established businesses. Some factors might have a different effect on women's established businesses' success than men's [3].

The promotion of female entrepreneurial activity is widespread among organizations like the World Bank, the Organization for Economic Cooperation and Development (OECD), and the World Trade Organization (WTO). According to the Morgan Stanley Capital International (MSCI) and the Financial Times Stock Exchange (FTSE) classification, Taiwan can be considered an emerging economy. According to various statistics, Taiwan made tremendous signs of progress according to the number of female-owned businesses, and therefore, the importance is increasing when it comes to entrepreneurship success among women. The FEI of Taiwan in 2015 scored 53.4, which is a very high value, and it got ranked in 26th place out of 77 [6,7]. It is crucial to shed light on female-owned businesses and to support them because, on the one hand, it empowers women, and on the other, it leads to poverty reduction and economic growth [8]. 
Compared to developed economies, women in emerging economies, especially in low-income regions/countries, are often more self-confident concerning their skills and doing their own business, shown in Figure 1 below. It visualizes the established business rate, which means that the business is at least 42 months old, which indicates the success of a business. A low established business rate harms the overall entrepreneurship and slows economic growth [3]. Established business ownership rate refers to the percentage of the 18-64 population who are currently owner-manager of an established business, i.e., owning and managing a running business with paid salaries, wages, or any other payments to the owners for more than 42 months [9].

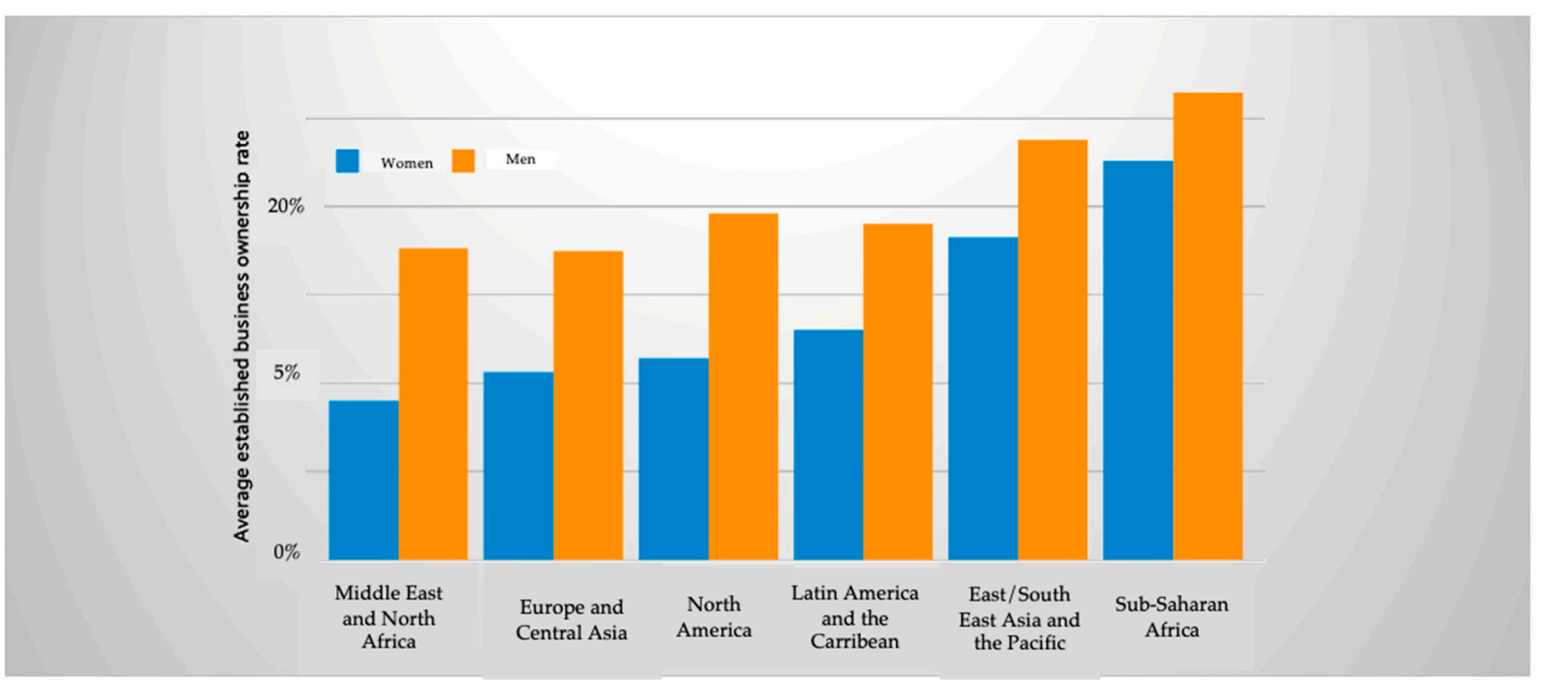

Figure 1. Average established business ownership rate by gender and region. Source: [3].

In the Middle East and Asia, gender disparity is a huge problem, and this issue is getting reduced by the expansion of entrepreneurship [10]. In Taiwan, more than $36 \%$ out of 1.46 million entrepreneurs are owned by women, and more than $51 \%$ of those businesses have a survival time of more than ten years, according to the "White Paper on Small and Medium Enterprises in Taiwan, 2016" [11]. Taiwan is well-known for many small- and medium-sized enterprises, where many women are involved, contributing to the labor market and developing the economy. Therefore, more governmental policy support for female business owners must be provided [12].

To sum it up, when it comes to female entrepreneurship in emerging markets, it is clearly shown that two main problems/challenges are existing:

1. Women tend to start businesses with lower growth and profit expectations;

2. Unemployment and gender disparity are huge issues, especially in high-income regions/countries like Taiwan.

The paper investigates how economic growth could be achieved by increasing the number of successful female entrepreneurs due to the mentioned theoretical facts. Therefore, some factors are going to be analyzed to find out which factors have an impact on the established business rate among female entrepreneurs in Taiwan.

Much research exists on highly-developed economies, but studies on female entrepreneurship in emerging markets are scarce, especially those primarily focusing on Taiwan. Entrepreneurship is essential to drive economic growth, and so it is essential to shedding light on the creation of businesses by female entrepreneurs to highlight the value that female entrepreneurs bring to global societies and enhance further growth. Especially in emerging economies, it is the main contributing factor to social progress and the economy as a whole, and it is an essential driver for the industrial competitiveness and opportunities of employment $[2,13,14]$. 
According to the literature, more intensive research is suggested regarding the correlation between personality traits and entrepreneurial activity, focusing on the factors influencing the established business rate to determine relevant success factors [12]. Most of the literature analyzed factors responsible for a successful business start, but less research was found on the factors affecting an already successful, established business, which is at least 42 months old [15].

The following research question will be answered by combining secondary and primary data:

"What factors contribute significantly to female entrepreneurs' business success in Taiwan?"

To limit the research, not all issues will be analyzed. Therefore, male-dominated entrepreneurship and general basics about entrepreneurship are not the subject of that paper and will not be described in detail since the empirical part will only focus on female entrepreneurs' success factors in Taiwan.

\section{Literature Review}

The following section summarizes the literature findings and highlights the relevant topics of that paper. It should be noted here that the summary of the literature is not intended to be exhaustive. Instead, the focus is on those theoretical backgrounds that are important for the present paper.

\subsection{Feminist Liberal and Social Theories}

First, the theoretical approach, which is building the basis of that paper, will be discussed. It deals with the feminist liberal and social theories and Hofstede's cultural dimensions to examine the differences between women's characteristics and behavior in Taiwan [16]. According to Thornton et al. [17], social and cultural aspects significantly impact becoming an entrepreneur and founding their own business. In the literature, the most mentioned entrepreneurship drivers, especially for the female gender, are worries about failing, available resources and income, recognized chances, and role models [18]. Due to women being more afraid of failing than men, Koellinger et al. assume that this leads to the differences in entrepreneurial activities by gender [18]. Especially in the Asian culture, the face concept plays an important role, and it is part of Asians' being. Losing one's face is a definition for losing others' respect, which might be why Asian people have a certain degree of fear of failure because it is part of their culture to maintain their face. They work their whole life on their reputation and prestige, and they do not want to risk that. It is also often the case that face is getting lost because of others, like employees. When it comes to the loss of face, it is usually connected to shame, and people want to hide, which often leads to the loss of power, alienation, and social isolation [19].

\subsection{Level of Awareness on Entrepreneurial Competencies}

Second, it is widely agreed that women have a lower awareness of their entrepreneurial competencies, particularly in male-dominated sectors. Men are more confident concerning their skills, impacting entrepreneurial intentions [20]. According to Shane and Venkataraman [21], the identification and exploitation of opportunities is the most meaningful entrepreneur characteristic. The literature also assumes that the probability of becoming an entrepreneur and starting a business is higher when people are in an entrepreneurial environment, so if a company is employing many young people, the entrepreneurial intentions in that company will increase. Furthermore, role models play an essential role when it comes to the perception of entrepreneurial skills. Therefore they are vital for female entrepreneurs [22].

\subsection{Factors for the Determination of Business Success}

In this context, success factor research is dedicated to identifying positive influencing factors that impact entrepreneurship's success. Many scientists believe that it is impossible 
to develop a conclusive theory that describes why some start-up projects fail, whereas other young companies grow in the long term [23]. Therefore, success factor research has gradually broken down into different sub-areas that can be broken down into two main research streams at a higher level. This is because one part of the research focuses on external factors, while other research focuses on internal success determinants [24]. Other authors, like Gartner [25], consider internal and external success factors and emphasize the great importance of the availability of qualified employees and suppliers, the barriers to market entry, the quantity and quality of the competitors as well as the legal framework for the determination of the success of a company.

There is no uniform understanding of how its success is determined neither in the external nor internal success factor research. One possible reason for the inconsistent research results can be the different random samples, which differ, among other things, concerning the age of the company or the industry under consideration. The inconsistent operationalization of success and its determinants could also cause mixed research results [26].

The FEI (Female Entrepreneurship Index) from the Global Entrepreneurship and Development Institute shows various factors favorable for female entrepreneurs' success. In 2015, 77 regions/countries and 33 indicators were analyzed for the index. The indicators were summarized to the following 15 pillars [9].

Due to space limitations, not all factors can be analyzed. Therefore some specific factors were chosen, which were also found in various other scientific papers and journals, as indicated in Figure 2. Furthermore, the data analysis will be mainly based on a secondary metadata-analysis, and therefore it is vital that data could be extracted from the GEM database, which is used for the data analysis:

- Pillar 2: Start-up skills (Education)

- Pillar 3: Willingness and Risk (Fear of Failure)

- Pillar 4: Networking (Personal Network)

Sub-index 1:

Enterpreneurial environment

Pillar 1: Opportunity perception

Opportunity recognition

Equal Rights \& market size

Pillar 2: Start up skills

Perception of skills

Secondary education

Pillar 3: Willingness and Risk

Willingness to start

Business risk

Pillar 4: Networking

Know an entrepreneur

Access to internet \& networks

Pillar 5: Cultural Support

Executive status

Access to childcare
Sub-index 2:

Enterpreneurial ecosystem

Pillar 6: Opportunity start-up

Opportunity business

Business freedom

Pillar 7: Technology sector

Tech sector business

Tech absorption

Pillar 8: Quality of Human resources Highly educated owners

Small business support \& training

Pillar 9: Competition

Innovativeness

Monopolized markets

Pillar 10: Gender gaps

Entrepreneurship ratio

Labor force parity
Sub-index 3:

Enterpreneurial aspirations

Pillar 11: Product innovation

New product

Technology transfer

Pillar 12: Process innovation

New technology

$R \& D$ expenditure

Pillar 13: High growth

Business gazelles

Leadership

Pillar 14: Internationalization

Export focus

Globalization

Pillar 15: External financing

First-tier financing

Third-tier financing

Figure 2. Factors determining the business success of a female entrepreneur. Source: [9]. 
With the second pillar, women with start-up skills are filtered, who also possess secondary education as a minimum. Subsequently, the third pillar looks at females where the level of risk propensity is very high and where the fear of failure is not inhibiting the founding of a business. According to available financial data, the general business risk, legal belongings, and institutional assistance of intercompany transfers will be measured too with that pillar. The Networking pillar shows the number of women who have a personal connection to other entrepreneurs who founded a venture within the previous two years and possess networking possibilities. Cultural support is also a relevant pillar when it comes to the Entrepreneurial environment because it shows women with access to childcare on an affordable basis and a good-quality level, and it measures the number of women who do not take the opinion that men are better than women when it comes to the execution of businesses [10].

The second sub-index, the Entrepreneurial ecosystem, the opportunity start-up pillar, considers the female business activity of young and nascent entrepreneurs and the freedom of movement. The degree of female business activity in the technological sector is measured by pillar seven and the general technology absorption level. The degree of education and the guidance of small- and medium-sized enterprises are analyzed in the human resources pillar quality. The pillar competition is captured by female ventures, which have only a few competitors with similar services or products, and monopoly markets are considered. The last pillar within that sub-index is dealing with the topic of gender-parity where the relation of the entrepreneurial activity between women and men gets essential [10].

When it comes to the third sub-index entrepreneurial aspirations, another five pillars are defined:

1. The product innovation represents female entrepreneurs who provide a completely new product to the market and also the transfer of technology, which combines research and development investments, the existence of research institutions with a high level of quality, the protection of intellectual property rights, and the cooperation between industries and universities.

2. The innovation process captures technologies younger than five years by female entrepreneurs and their expenses on research and development concerning the GDP.

3. High growth represents women who have the vision to expand their business to more than $50 \%$ and want to employ a minimum of ten people in the next five years.

4. The pillar shows the region/country's total number of female managers.

Subsequently, the pillar internationalization is analyzed by the number of femalefound businesses, which are exporting goods and services globally. The last pillar is about external financing of female entrepreneurs and considers the accessibility to financing through a bank account or finance programs and equity capital availability [10].

To sum it up, the three main findings in existing literature are the theories about social-cultural factors, the level of awareness on entrepreneurial competencies, and the success factors of female entrepreneurs.

\section{Materials and Methods}

\subsection{Conceptual Framework}

A research framework illustrated in Figure 3 had to be developed. It helps the authors focus on the scope and to reach the objectives by defining and identifying different variables and is usually connected to the research question [27]. The whole research is focused on female entrepreneurs so that the research will take place within that frame. The research data will be analyzed by logistic regression, where the influence and the relationship between one dependent and various independent variables will be tested. The independent variables will be changed, and the change's impact will be measured with the dependent variable. Therefore, the authors chose various success factors, which seemed very relevant according to the literature review. Those factors are the independent factors that might influence the dependent variable. The dependent variable is called established businesses of female entrepreneurs, where data from the GEM database is retrieved. It has 
to be noticed that each relationship between one independent and the dependent variable has to be tested separately because some might have an influence in a negative way and some in a positive way. It is also necessary to identify some control variables, which may influence the outcome, and they need to be controlled and stay constant. The control variables the authors identified are age and region/country. The advantage of taking care of control variables is that the research's reproduction can be done more straightforwardly, and the research results' confidence is increasing [28].

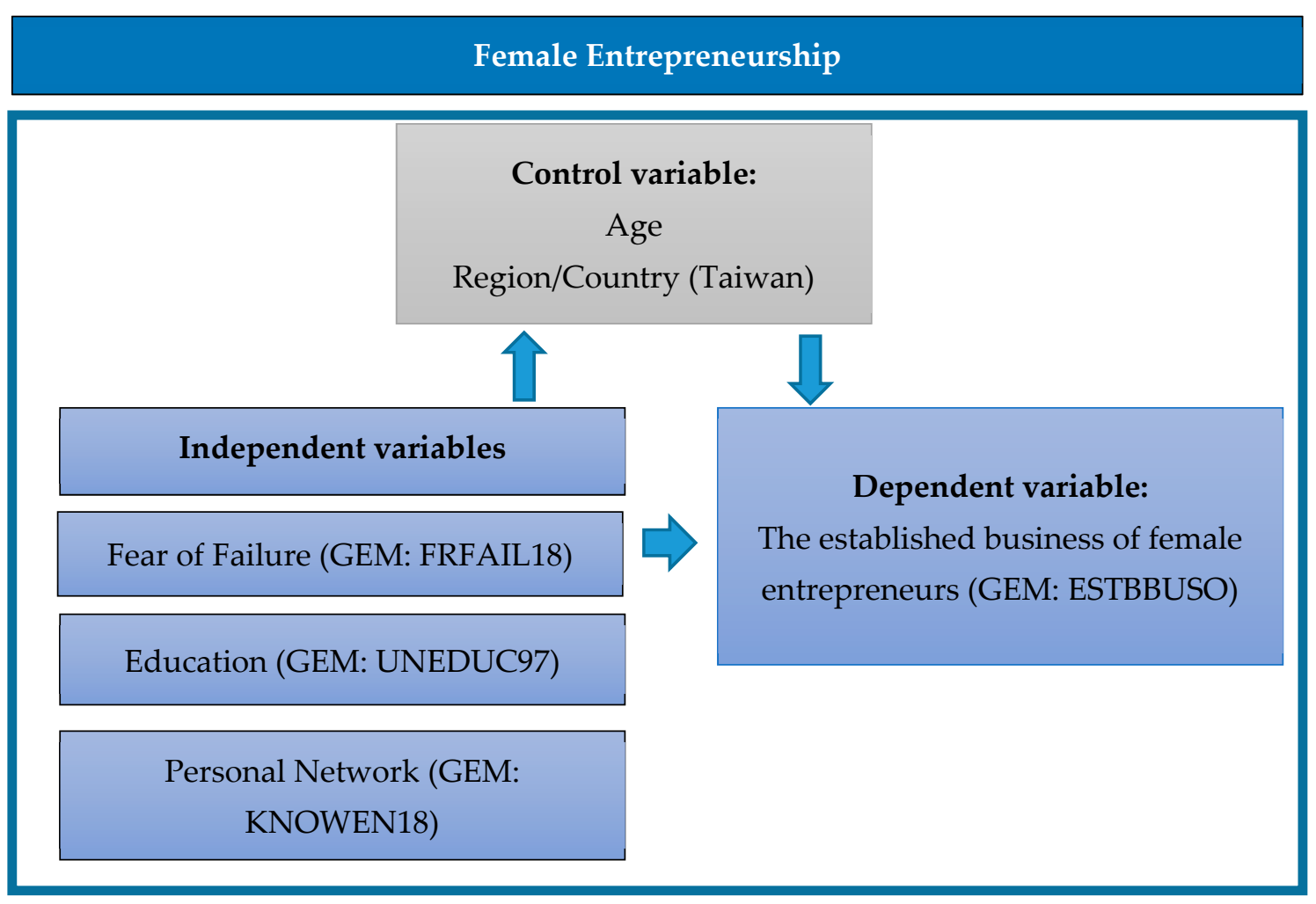

Figure 3. Research framework.

\subsubsection{Source of Data}

The study's subject was the participants of the Adult Population Survey (APS) from the GEM database. To get the data only from the target group, the database was filtered to get only female participants from Taiwan, aged between 18 and 64. In total, the database includes 1098 observations of women in Taiwan and 117 interviews.

\subsubsection{Data Analysis}

Due to limitations, not all factors could have been analyzed by the authors. Therefore, some specific factors were chosen, which were also found in various other scientific papers and journals. Furthermore, the data analysis was mainly based on a secondary metadataanalysis, and therefore it is essential that data about these factors could be extracted from the GEM database, which is used for the data analysis. For the analysis and the interpretation, the statistical tool " $\mathrm{R}$ " was used. The logistic linear regression model was used to identify the relationship between one or more independent variables and one dependent variable. Oversampling was also used while a dataset was not balanced, and the answers of the dependent variable were dominated by one single value, which might manipulate the data analysis. Therefore, it was essential to modify and balance the data to use the dataset for the statistical analysis. 


\subsection{Hypotheses}

In general, entrepreneurship is determined by several success factors, which were described in the sections above. This paper will focus on some specific success factors of an established business to test them concerning female entrepreneurship and individual region/country-level. The following section will explain the motives that drive female entrepreneurs' success.

\subsubsection{Education}

According to the literature, professional experience and education are essential success factors for entrepreneurship and have a massive influence on entrepreneurial skills and self-employment. On the one hand, it leads to the acquisition of specific qualifications. On the other hand, it is about the stimulation of unique characteristics concerning one's initiative and self-control to get the ability and courage to implement one's ideas and thoughts-more or fewer self-employment opportunities mark certain occupational areas. The choice of a particular occupation is already a preliminary decision for or against self-employment [29].

A curriculum that integrates entrepreneurial subjects is widespread nowadays to raise awareness of entrepreneurship's possibilities and opportunities. Especially in institutions on a secondary or tertiary level, skills, knowledge, and attitudes about entrepreneurship are transferred. Through that approach, entrepreneurial mindsets, thoughts, and talents are getting fostered, leading to a reduction of entrepreneurial barriers [30].

The entrepreneurial skills could be distinguished between the learnable qualifications and between certain personality traits, which have a high degree of stability over time. Especially the variety and the structure of qualifications are relevant for successful entrepreneurship. According to literature research, it could be assumed that a positive correlation between the educational level and the probability of having a business is existing [28]. Mainly, nowadays, it could be observed that women with higher educational levels are more focused on self-employment [11].

Most female entrepreneurs in Taiwan are educated with primary and secondary education and are aged between 30 and 40 [11]. According to Hofstede's cultural dimension "Masculinity vs. Femininity," Taiwan can be assigned to a slightly feminine culture because it has a relatively low score of 45 , which means that people are somewhat motivated by doing their task because they like it, instead of trying to be better than the others. The culture appreciates more the quality of life [16].

Therefore, the following hypothesis could be formed:

Hypotheses (H1). The factor "level of education" is significantly correlated to business success among females in Taiwan.

\subsubsection{Risk Awareness and Fear of Failure}

Fear of failure is a factor that exists among both genders. Nevertheless, the degree of fear of failure is much higher among women. When it decides the expansion of the business by women, factors like risk aversion, lack of awareness of own competencies, and the aspiration of a work-life balance often hinder that decision. Due to the higher degree of fear of failure, female entrepreneurs tend to grow businesses longer and do not want to expand their businesses quickly. For women, it is essential to limit the size of a business to some extent in order to be able to manage and control the business with their available resources and skills and their desire for a work-life balance, so their risk propensity is relatively low. Besides the progress on gender equality, it is still the case that women are getting discriminated against at the workplace and feel they need to take care of the household and their family. That is why many women enjoy a business's ownership because that helps them get out of that stereotypical thinking and enables them to become more independent. Changing from an employee to a business owner is a crucial step when it comes to self-realization. The decision to own and expand a business is determined by a lot of personality traits and challenges. When women start a business, they show that they 
can overcome those barriers, and according to literature, it can be assumed that a higher degree of freedom on taking the risk and creating its working style can be reached [31].

Cities in Taiwan, which have a more considerable amount of men, show a higher number of self-employed because of better financial support and a higher awareness of risk. Furthermore, in Taiwan, the self-employment rate is very high in the following sectors according to the data from 2017: service and sales (38\%), agriculture and forestry (25\%), craft- and machine-operation (25\%). That is why it is more difficult for females in Taiwan to own a business because men usually dominate the mentioned sectors. Differences in the labor market can be observed when comparing developed countries in the European Union (EU) [31]. According to the cultural dimensions of Hofstede, it is shown that Taiwan has a substantial degree of uncertainty avoidance with a score of 69 , which indicates that the people with that culture do not feel comfortable when it comes to unknown or ambiguous situations, and they try to avoid them [16].

Based on the theoretical findings, the following hypotheses were formed:

Hypotheses (H2). The factor "fear of failure" is significantly correlated to business success among females in Taiwan.

\subsubsection{Personal Network}

When it comes to the start or expansion of female businesses, family and friends' support plays an important role. The acknowledgment of the idea by people, who are in a close relationship with female business owners, is of high value [11]. Influences from outside and from the family are affecting the decision-making processes of women. Therefore, it can be assumed that personal contacts and role models are favorable to female entrepreneurs' business success [11]. The importance of family members or team members in the decision-making process also indicates that women have a more collaborative leadership style, and when it comes to achieving goals, teamwork is preferred by women. Informal networks for sharing information and resources among various enterprises are standard in female-owned businesses [12].

Considering Hofstede's cultural dimensions, Taiwan has a collectivistic culture with a score of 17 , which means that loyalty plays a crucial role, and healthy relationships are fostered [15]. In developing countries/regions, like China and Taiwan, social status is often a challenge among female entrepreneurs because they play a crucial role in entrepreneurial intentions. In many cases, the problem is that the family opposes new ventures because they had negative experiences with female entrepreneurship [11].

Therefore, the following hypotheses can be assumed:

Hypotheses (H3). The factor "personal network" is significantly correlated to business success among females in Taiwan.

\subsection{Research Design}

The literature review in the theoretical part built the basis for the empirical part and was needed to form the hypotheses tested by the authors through secondary data analysis. The literature review aimed to analyze significant determinants of female entrepreneurs business success in Taiwan to answer the research questions and the results analyzed by the authors with a metadata-analysis. The central database for the quantitative research was the freely accessible GEM database 2018/2019, which intends to analyze and report the entrepreneurial environment of 49 individual economies every year [32]. The sample size includes at least 2000 adults in every economy. The National Expert Survey (NES) is based on at least 36 experts for assessing the conditions of the creation of entrepreneurship in each economy. The database enables a region/country comparison on a high level, as it provides a detailed insight on different entrepreneurial types and phases (GEM Global Entrepreneurship Monitor, n.d.).

To answer the research questions and hypotheses, variables from the GEM database were extracted, reflecting the mentioned factors of education, fear of failure, personal 
network, opportunity perception, entrepreneurial skills, and role models to analyze their influence on the established business rate.

The study subjects were the participants of the Adult Population Survey (APS) from the GEM database. To get the data only from the target group that should be focused on in this paper, the database was filtered to get only female participants from Taiwan, aged between 18 and 64. In total, the database includes 1098 observations of women in Taiwan and 117 interviews.

For the analysis and the interpretation, the statistical tool " $\mathrm{R}$ " will be used. To identify the relationship between variables, the logistic linear regression model was used to determine if a prediction of the established businesses is possible through the various independent factors [33]. For example, in the case of that paper, the binary dependent variable would be the variable "established businesses," which can be either 0 for "No, the person is not an established business owner," or 1 for "Yes, the person is an established business owner," like in some other research [34,35].

To determine the factors of successful businesses of female entrepreneurs, together with some differences between females in emerging and developed economies, a secondary metadata-analysis was used, which has already been collected by the GEM-consortium. With that type of research, existing theories are used and are proven by the authors through the secondary data analysis, and therefore, hypotheses have to be formed. For that research approach, mainly external secondary data were used by the authors. Secondary research saves time and helps prepare the primary research, and it also provides additional relevant information. Although secondary data analysis has many advantages, some disadvantages also need to be considered. The purpose of the collected data is often deviating from the purpose of the current research, which could lead to a lack of relevance and accuracy. With Google Scholar, scientific articles and journals with a VHB Ranking of at least D were analyzed to get sufficient secondary data. Besides, some expert interviews were carried out to support and prove the findings and get some additional insights. The experts were chosen to discuss the results analyzed by the authors. Therefore, one expert from the GEM research team in Austria and one expert from the Taiwan team were interviewed.

\subsection{Data}

As already mentioned in the chapters above, the database for the secondary metadataanalysis is the GEM database. It provides entrepreneurial data of different regions/countries and analysis on entrepreneurial characters and inspirations. GEM can be considered one of the best initiatives regarding the research of entrepreneurial perceptions and attitudes among several regions/countries [3].

To be able to answer the research questions and hypotheses of that thesis, variables from the GEM database were extracted, which reflect the mentioned factors of education, fear of failure, and personal network.

\subsubsection{Dependent Variable}

The variable established business ownership "ESTBBUSO" will be used as the indicator of success in that master thesis and is therefore used as the dependent variable and identifies people managing and owning a business that is aged more than 42 months. It is a binary scaled variable with two levels. 0 means "No established business owner," and 1 means "Established business owner."

\subsubsection{Independent Variables}

The independent variables which are used to predict the established business owners are mainly nominally scaled variables and were recoded to binary variables by removing answers like "Do not know," "Refused," and "Not Answered" because they are not relevant for the analysis. It means that the variables' value can be 0 for "No" and 1 for "Yes." Except for "UNEDUC97", scaled ordinally with seven different educational levels, which were summarized by the authors in two categories: 0 for "lower education" and 1 for "higher 
education" by looking at the number of established businesses in each category and by splitting it into two categories to have approximately the same number of answers in both categories. The following table gives an overview of which success factors were chosen and how they are going to be connected to the data from the GEM database, as shown in Table 1.

Table 1. Selected success factors and the connection to GEM.

\begin{tabular}{|c|c|c|}
\hline Success Factors & GEM Variable & Levels \\
\hline \multirow{7}{*}{ Education } & \multirow{7}{*}{$\begin{array}{c}\text { UNEDUC97 } \\
\text { What is your level } \\
\text { of education? }\end{array}$} & 0: Lower educational level \\
\hline & & - $\quad$ Pre-primary education \\
\hline & & - $\quad$ Primary education \\
\hline & & $\begin{array}{l}\text { - Lower secondary education } \\
\text { - } \quad \text { (Upper) secondary education }\end{array}$ \\
\hline & & 1: Higher educational level \\
\hline & & - $\quad$ Post-secondary non-tertiary education \\
\hline & & $\begin{array}{l}\text { - The first stage of tertiary education } \\
\text { - The second stage of tertiary education }\end{array}$ \\
\hline \multirow{3}{*}{ Risk awareness } & fearfail & \multirow{3}{*}{$\begin{array}{l}\text { 0: "No." } \\
\text { 1: "Yes." }\end{array}$} \\
\hline & Would fear of failure prevent & \\
\hline & you from starting a business? & \\
\hline \multirow{4}{*}{$\begin{array}{l}\text { Personal } \\
\text { network }\end{array}$} & knowent & \multirow{4}{*}{$\begin{array}{l}\text { 0: "No." } \\
\text { 1: "Yes." }\end{array}$} \\
\hline & Do you know someone & \\
\hline & personally who started a & \\
\hline & business in the past two years? & \\
\hline
\end{tabular}

\subsection{Logistic Regression Model}

The binary logistic regression analysis investigates the relationship between the probability that the dependent variable takes the value 1, which means "Yes, the person is an established business owner," and the independent variables. So, it has to be mentioned that the dependent variable's value is predicted, but it is predicted that the dependent variable takes the value 1 [36].

The following conditions have to be fulfilled when logistic regression is used:

- $\quad$ The dependent variable is binary (either 0 or 1 ).

- The independent variables need to be metric or binary dummy variables.

- $\quad$ For each group formed by categorical predictors, $n \geq 25$.

- The independent variables are not positively correlated with each other.

The logistic regression model is based on maximum-likelihood estimation. Like the linear regression model, the logistic regression analysis tries to find a curve that fits the data well. The function is not linear. It is "s-shaped" symmetrical and runs asymptotically towards $y=0$ and $y=1$. This means that the logistic function only takes values between 0 and 1 [37].

The following formula is behind the logistic regression model:

- $\quad P$ : the probability that the dependent variable $(y)$ is 1 .

- $\quad e$ : the basis of the natural logarithm, Euler's number.

- $z$ : linear regression model of the independent variable, which is also called logit.

- $x_{k}$ : independent variable.

- $\quad \beta_{k}$ : regression coefficient, which shows if the independent variable is negatively or positively correlated to the dependent variable.

- $\quad \varepsilon$ : error value, which measures the difference between the value predicted by the regression line for the test person and the measured value for the test person.

$$
P(y=1)=\frac{1}{1+e^{-\left(\beta_{0}+\beta_{1} \cdot x_{1}+\beta_{2} \cdot x_{2}+\cdots \beta_{k} \cdot x_{k}+\varepsilon\right)}}
$$


After inserting the relevant variables, the following formula can be used:

$$
P(\text { ESTBBUSO }=1)=\frac{1}{1+e^{-\left(\beta_{0}+\beta_{1} \cdot \text { FRFAIL18 }+\beta_{2} \cdot \text { KNOWEN18+ } \beta_{3} \cdot \text { UNEDUC97 }\right)}}
$$

The formula calculates how likely the independent variables can predict the value of a dependent variable. The value of the likelihood function can also be used to estimate the model quality and model significance. The $p$-value and the chi-square value for the whole model have to be analyzed to test its significance. When the value is below 0.05 , it indicates the statistical significance, and the null hypothesis can be rejected. The Wald test shows the significance of each factor and is necessary to test the hypotheses for each factor, and it is helpful to find out which factors should not be integrated into the model because they are not statistically significant. The goodness of the fitness of a model is going to be tested with the R-square value. In the logistic regression analysis, the Negelkerke R-square value is standard and is between 0 and 1, and the closer the value is at 1 , the better the model fits the regression, and it shows how close the variability of the data is around the mean.

Due to limitations regarding this paper's scope and the limited amount of available data, not all factors can be part of the study. Therefore some socio-cultural factors from the FEI were chosen, which were also found in various other scientific papers and journals [38-40].

The data analysis will be mainly based on secondary metadata-analysis, and therefore, it is essential that these factors could be extracted from the GEM database, which is used for the data analysis. Of course, there are much more factors that relate to entrepreneurial business success; however, at this point, the focus shall remain on the matters relevant to the scope of this paper and leave other issues open for further discussions and researchers.

The study's subject is the Adult Population Survey participants (APS) from the GEM database. The database was filtered to get only female participants from Taiwan and Austria, aged between 18 and 64. In total, the database includes 1098 observations of women in Taiwan and 2270 female participants from Austria.

The variable established business ownership "ESTBBUSO" was used as the indicator of success and is therefore used as the dependent variable and identifies people managing and owning an older enterprise than 42 months. It is a binary scaled variable with two levels. 0 means "No established business owner," and 1 means "Established business owner."

The independent variables which are used to predict the established business owners are mainly nominally scaled variables and were recoded to binary variables by removing answers like "Do not know," "Refused," and "Not Answered" because they are not relevant for the analysis. It means that the variables' value can be 0 for "No" and 1 for "Yes." Except for the variable "UNEDUC97", which is scaled ordinally with seven different educational levels, other variables were summarized by the authors in two categories: 0 for "lower education" and 1 for "higher education" by looking at the number of established businesses in each category and by splitting it into two categories to have approximately the same number of answers in both categories. The following table gives an overview of which success factors were chosen and how they are going to be connected to the data from the GEM database as shown in Table 2. 
Table 2. Selected success factors and the connection to GEM.

\begin{tabular}{|c|c|c|}
\hline Success Factors & GEM Variable & Levels \\
\hline \multirow{5}{*}{ Education } & \multirow{5}{*}{$\begin{array}{c}\text { UNEDUC97 } \\
\text { What is your level of education? }\end{array}$} & 0: Lower educational level \\
\hline & & - $\quad$ Pre-primary education \\
\hline & & $\begin{array}{ll}\text { - } & \text { Primary education } \\
\text { - } & \text { Lower secondary education } \\
& \text { (Upper) secondary education }\end{array}$ \\
\hline & & 1: Higher educational level \\
\hline & & $\begin{array}{l}\text { - } \quad \text { Post-secondary non-tertiary education } \\
\text { - } \quad \text { First stage of tertiary education } \\
\text { - } \quad \text { Second stage of tertiary education }\end{array}$ \\
\hline \multirow[b]{2}{*}{ Risk awareness } & \multirow{2}{*}{$\begin{array}{c}\text { fearfail } \\
\text { Would fear of failure prevent you from starting } \\
\text { a business? } \\
\text { knowent }\end{array}$} & $0:$ “No" \\
\hline & & 1: "Yes" \\
\hline Personal network & $\begin{array}{c}\text { knowent } \\
\text { Do you know someone personally who started a business } \\
\text { in the past } 2 \text { years? } \\
\text { opport }\end{array}$ & $\begin{array}{l}\text { 0: "No" } \\
\text { 1: "Yes" }\end{array}$ \\
\hline Opportunity perception & $\begin{array}{l}\text { In the next six months, will there be good opportunities } \\
\text { for starting a business in the area where you live? } \\
\text { suskill }\end{array}$ & $\begin{array}{l}\text { 0: "No" } \\
\text { 1: "Yes" }\end{array}$ \\
\hline Entrepreneurial skills & $\begin{array}{c}\text { Do you have the knowledge, skill and experience } \\
\text { required to start a new business? } \\
\text { nbstatus }\end{array}$ & $\begin{array}{l}\text { 0: “No" } \\
\text { 1: "Yes" }\end{array}$ \\
\hline \multirow{2}{*}{ Role model } & \multirow{2}{*}{$\begin{array}{c}\text { In your region/country, do those who are successful at } \\
\text { starting a new business have a high level of status } \\
\text { and respect? }\end{array}$} & 0: “No" \\
\hline & & 1: "Yes" \\
\hline
\end{tabular}

\subsection{Oversampling}

Oversampling is used if a dataset is not balanced, and the answers of the dependent variable are dominated by one single value, which might manipulate the data analysis. Therefore, it is essential to modify and balance the data to use the statistical analysis dataset. It means that the number of records of the minority class is increased. In contrast to the oversampling technique, the undersampling technique balances the data by reducing the majority class. The oversampling technique was chosen because no data is getting lost, and all binary values are kept. It means that the number of "Yes" answers is increased through the oversampling technique so that a balance between answers is produced. The random oversampling uses random participants with "Yes" answers, which are added and duplicated to the latest training dataset, as shown in Figure 4. The oversampling technique is only used to train the model. Otherwise, it would manipulate the results [41].

\subsection{Target Group}

The study's subject is the Adult Population Survey (APS) from the GEM database. To get the data only from the target group, the database was filtered to get only female participants from Taiwan, aged between 18 and 64. In total, the database includes 1098 observations of women in Taiwan. 


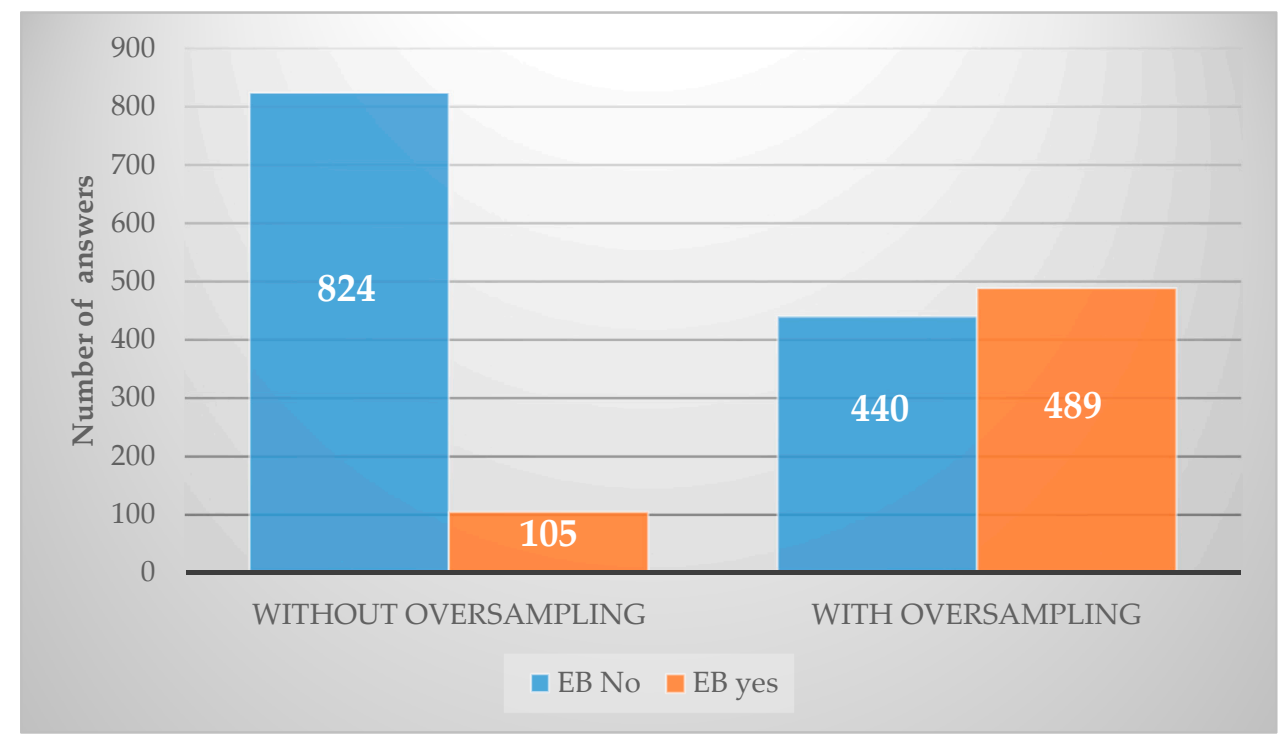

Figure 4. Comparison between real data and oversampled data.

\section{Results}

The following section shows the results observed by using GEM as the basis for the data analysis. The oversampling technique was used to balance the number of established business owners and non-established business owners. Therefore, the statistical tests were done with oversampled data. The method is only used to train the model. The descriptive results are done without overbalancing. Furthermore, missing answers like "NA" were filtered and omitted. At first, some insights on descriptive statistics will be shown, and afterward, the statistical test will be explained.

\subsection{Descriptive Statistics}

According to the descriptive statistics, a tendency is visible when it comes to the personal network factor. Participants had to answer the following question: "Do you know a person who started a business in the last two years?" Figure 5 below shows that the number of established businesses was 68 when female participants said they know a person who started a business in the last two years. Forty-five established business owners did not have a personal network with a recent business owner.

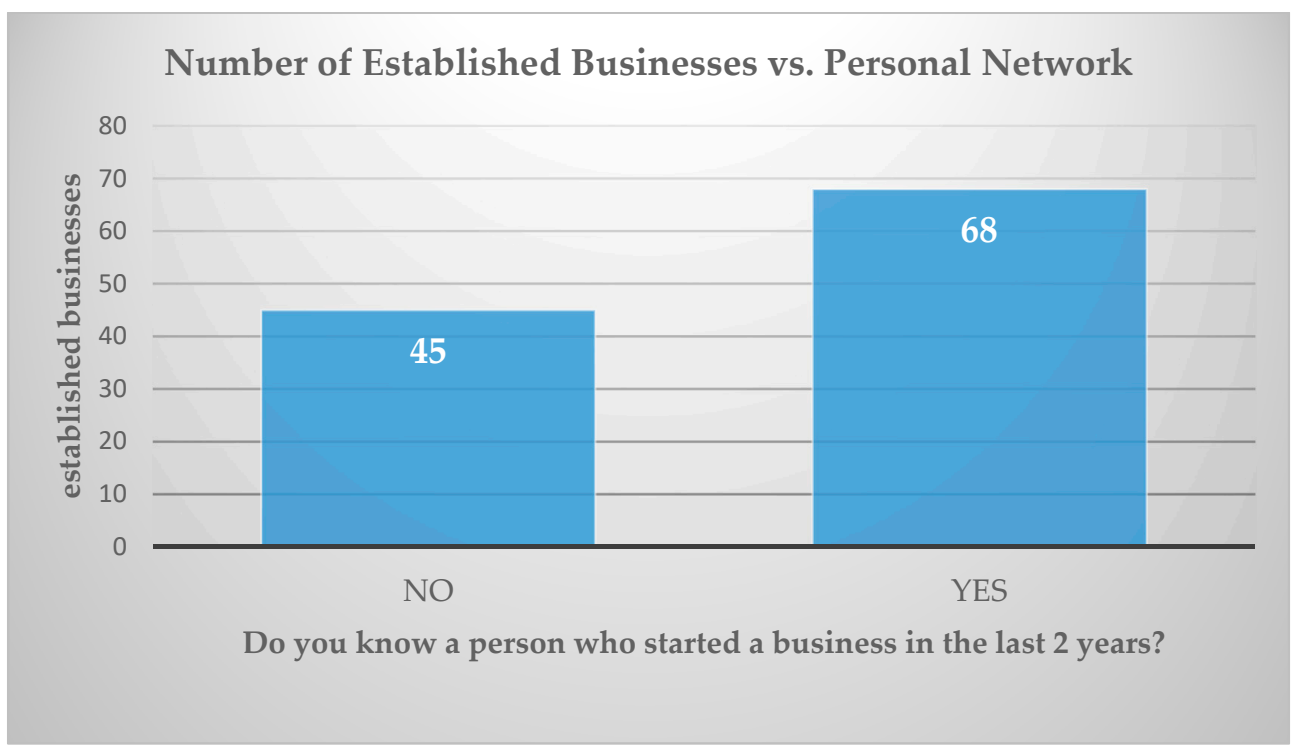

Figure 5. Number of established businesses vs. personal network. 
The following bar plot in Figure 6 shows the number of female established businesses compared to the number of participants who mentioned that fear of failure prevents them from doing business. Eighty-three established business owners said that that fear of failure does not prevent them from doing business, and 34 female entrepreneurs confirmed that fear of failure is a factor that is a barrier to doing business. Furthermore, it can be assumed that 117 female participants in Taiwan are owners of an established business after analyzing the data.

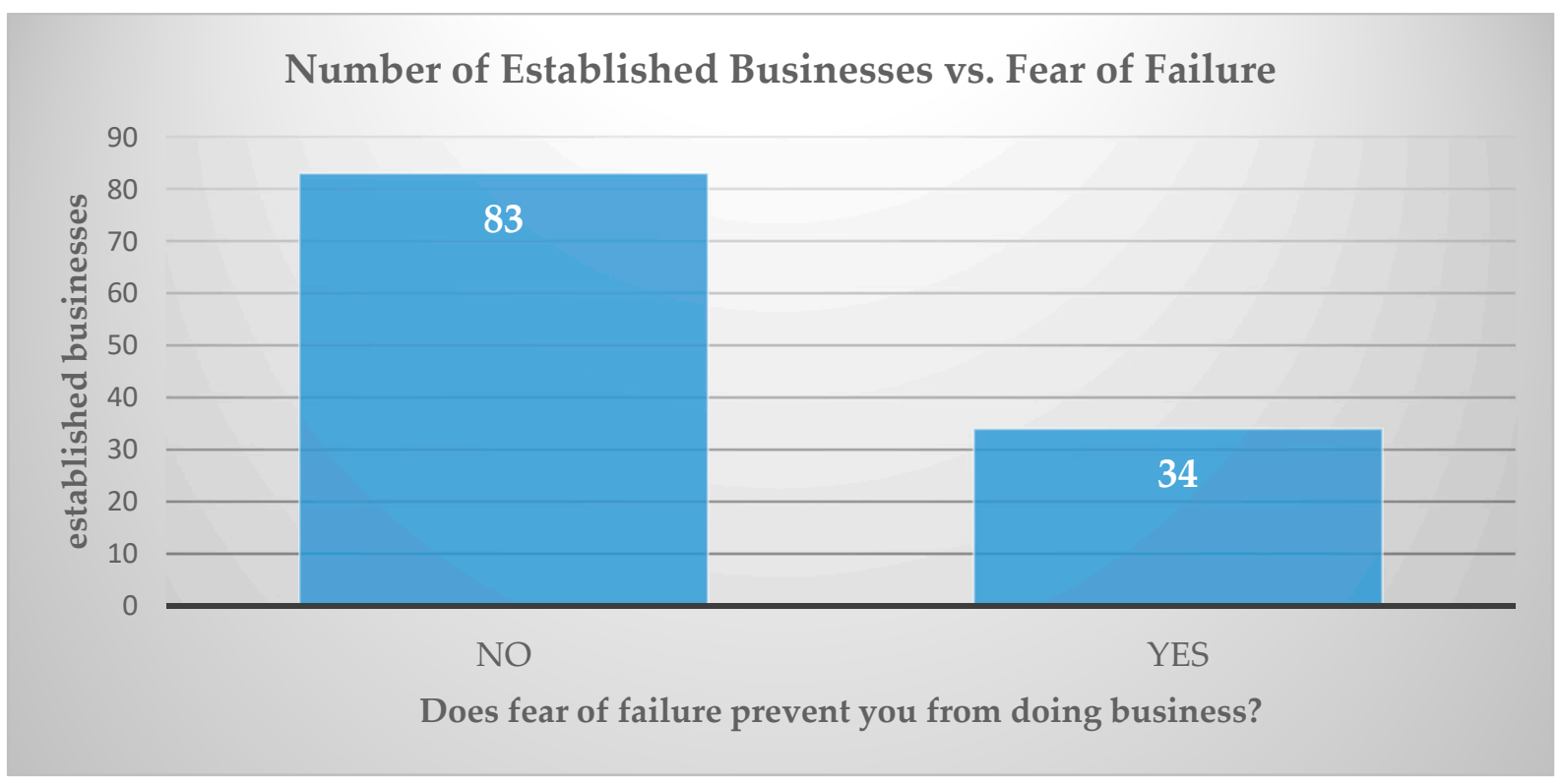

Figure 6. Number of established businesses vs. fear of failure.

When it comes to the Level of Education factor, the data is distributed among six different educational levels. The highest educational level and the lowest were only mentioned once. According to the post-secondary non-tertiary education, 29 are owning an established business, and 50 participants said that they have a lower to upper secondary education, as shown in Figure 7. When it comes to tertiary education levels, around 64 female participants are established business owners.

\section{Established businesses vs. Level of Education}

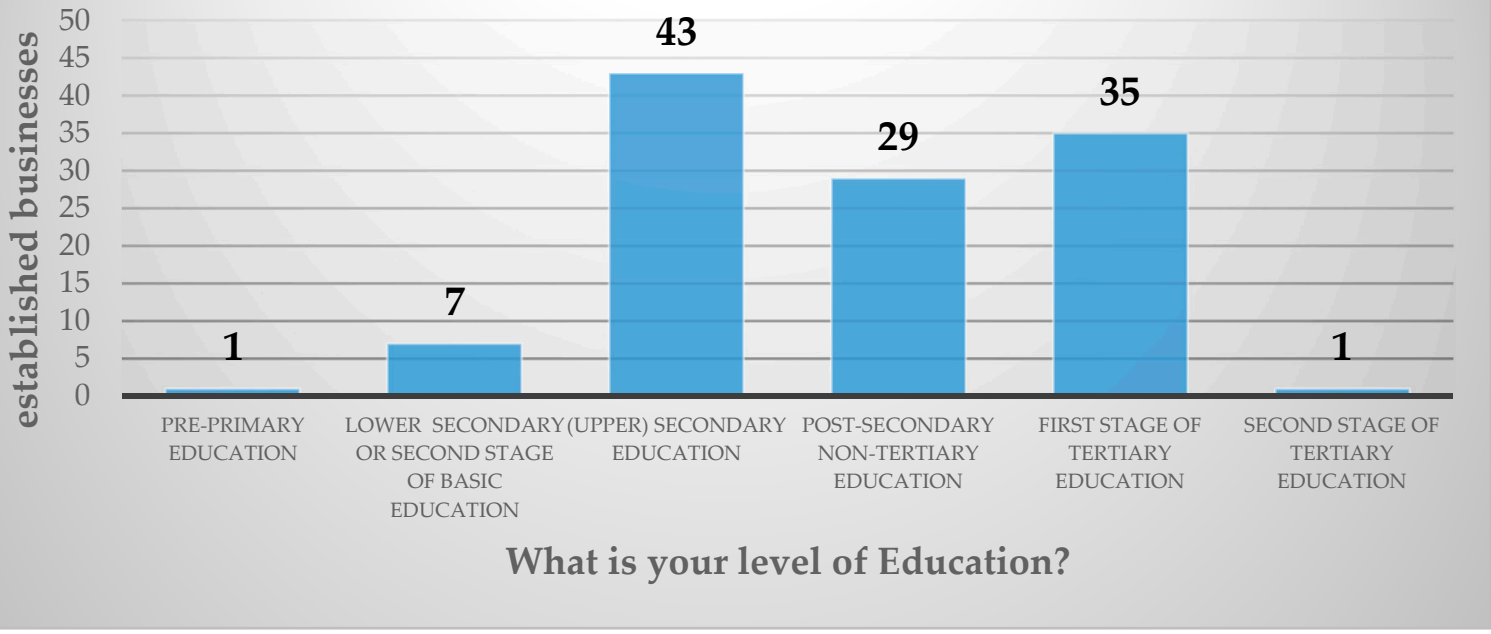

Figure 7. Number of established businesses vs. level of education. 


\subsection{Logistic Regression Model}

In order to analyze if the number of established businesses of females in Taiwan can be predicted through some specific factors, like fear of failure, educational level, and personal network, the logistic regression model was built in R, and the following results arise after oversampling the data:

\begin{tabular}{lrlrlr}
\multicolumn{5}{c}{ Lrm(formula $=$ model, data $=$ data2, $\mathrm{x}=$ TRUE, $\mathrm{y}=$ TRUE $)$} \\
Model Likelihood & & & & \\
Ratio Test & & Discrimination Indexes & Rank Discrim. Indexes \\
LP chi2 & 86.00 & R2 & 0.104 & C & 0.655 \\
d.f. & 3 & g & 0.647 & Dxy & 0.311 \\
Pr(> chi2) & $<0.0001$ & gr & 1.909 & gamma & 0.391 \\
& & gp & 0.153 & tau-a & 0.155 \\
& & Brier & 0.230 & &
\end{tabular}

To examine the significance of each coefficient, the authors performed the Wald test with the following relevant results regarding "Chi-Square" and " $\mathrm{P}$ ":

\$ 'Tests pro Predictor/Factor.'

$\begin{array}{llll} & \text { Wald Statistics } & & \text { Response: } \\ \text { Factor } & \text { Chi-Square d.f. } & & \text { ESTBBUSO } \\ \text { KNOWEN18 } & 44.6 & 1 & <0.0001 \\ \text { FRFAIL18 } & 35.67 & 1 & <0.0001 \\ \text { UNEDUC97 } & 0.55 & 1 & 0.4588 \\ \text { TOTAL } & 79.19 & 3 & <0.0001\end{array}$

It shows that the independent variables like "personal network" (KNOWEN18) and "fear of failure" (FRFAIL18) have a $p$-value which is below 0.0001, which is an indicator for statistical significance when it comes to the relationship between dependent and independent variables. Concerning the factor educational level, the $p$-value is considered relatively high with a value of 0.4588 , indicating no statistical significance. The regression coefficient and the odds ratios show that "Yes answers" of the personal network have a positive effect on the number of established businesses and, therefore, increase the number of established businesses. Fear of failure's coefficient shows that "Yes answers" negatively influence the established business and decrease established businesses.

The regression with the variable educational level shows a positive coefficient, which indicates that a higher educational level is positively related to the number of established businesses. Nevertheless, the examined relationship between the educational and established businesses is not statistically significant because of the $p$-value $>0.05$.

\begin{tabular}{lllll} 
& Coef & S. E. & Wald Z & $\operatorname{Pr}(>$ IZI $)$ \\
Intercept & -0.2084 & 0.2476 & -0.84 & 0.4001 \\
KNOWEN18 = Yes & 0.8601 & 0.1288 & 6.68 & $<0.0001$ \\
FRFAIL18 = Yes & -0.7849 & 0.1314 & -5.97 & $<0.0001$ \\
UNEDUC97 = 1 & 0.1860 & 0.2510 & 0.74 & 0.4588 \\
\$'Odds Ratios: exp(B) & & & & \\
Intercept & KNOWEN18 = Yes & FRFAIL18 = Yes & \multicolumn{2}{l}{ UNEDUC97 = 1} \\
0.8118835 & 2.3635151 & 0.4561655 & \multicolumn{2}{l}{1.2044142}
\end{tabular}

Various R-square tests were performed to assess how well the regression model explains the dependent variable. The pseudo R2 of "Negelkerke" can take values between 0 and 1 . The closer the value is to 1 , the better the regression. For the research of that paper, the value of the "Negelkerke R-square" is 0.1040776.

The classification is shown in the table below with an overview of how the system's predicted values were correctly predicted. It is visible that around $62 \%$ of the values were correctly classified, which is relatively low. 
\$ Classification

Observed

$\begin{array}{cc} & \text { No } \\ \text { No } & 306 \\ \text { Yes } & 212\end{array}$

\$ Share of correctly classified cases [1] 0.611898

\section{Results and Discussion}

In order to analyze if the number of established businesses of females in Taiwan can be predicted through the mentioned factors of fear of failure, educational level, personal network, role model, opportunity perception, and entrepreneurial skills, the logistic regression model was built in Jamovi, and the following results (Figure 8) arose after oversampling the data.

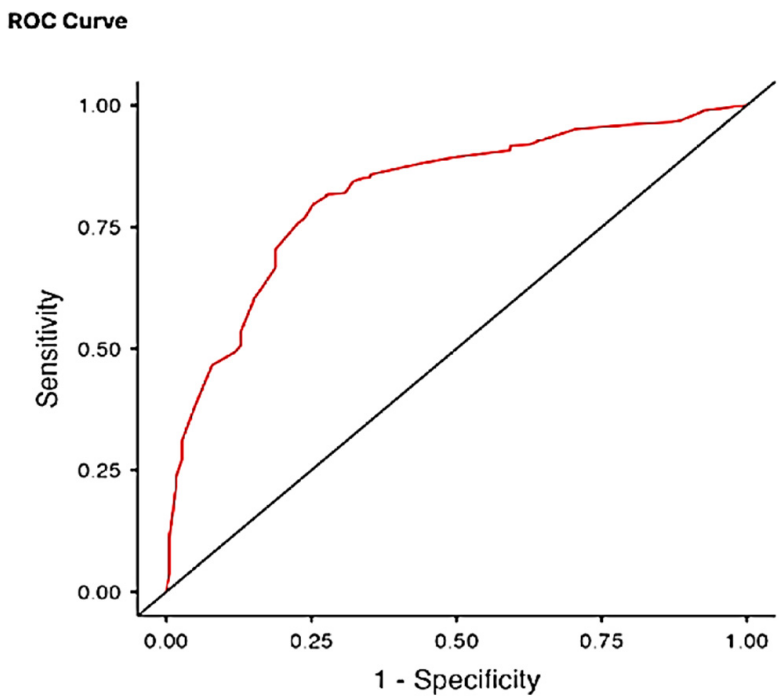

Figure 8. ROC analysis (Taiwan).

To examine each coefficient's significance, the system performed the Omnibus Likelihood Ratio Test with the following relevant results in the columns "chi-square" and "p."

It shows that the independent variables like "knowent," "suskill," "opport," and "UNEDUC97" have a $p$-value which is below 0.001, which is an indicator for a statistical significance when it comes to the relationship between dependent and independent variables. Concerning the factor "nbstatus," the $p$-value is considered rather high with a value of 0.329 , indicating no statistical significance. Therefore, the factor "nbstatus" is going to be excluded from the model. The AIC value and the $p$-value 0.329 show that the variable "nbstatus" does not increase the quality of the prediction, and therefore the model without that variable will be preferred, as shown in Table 3.

Table 3. Omnibus likelihood ratio test to verify the significance of each variable-Taiwan.

\begin{tabular}{ccc}
\hline Predictor & X2 & $p$ \\
\hline suskill & 397.521 & $<0.001$ \\
UNEDUC97 & 23.624 & $<0.001$ \\
fearfail & 11.057 & $<0.001$ \\
opport & 10.885 & $<0.001$ \\
knowent & 10.062 & 0.002 \\
nbstatus & 0.945 & 0.329 \\
\hline
\end{tabular}

The regression coefficient and the odds ratios show that "yes" answers of the personal network ("knowent") have a positive effect on the number of established businesses as 
well as the "yes" answers of the factor entrepreneurial skills ("suskill") and therefore might increase the number of established businesses. The coefficient of fear of failure shows that "Yes" answers negatively influence the established business and decrease the number of established businesses.

The regression with the variable educational level shows a result in Table 4 with a negative coefficient too, which indicates that a higher educational level is negatively related to the number of established businesses and opportunity perception ("opport").

Table 4. Coefficients of the reduced model of Taiwan (Jamovi).

\begin{tabular}{ccc}
\hline Predictor & Estimate (B) & Odds Ratio \\
\hline suskill & 2.415 & 11.36 \\
UNEDUC97 & -0.616 & 0.54 \\
fearfail & -0.413 & 0.66 \\
Opport & -0.476 & 0.63 \\
Knowent & 0.406 & 1.50 \\
\hline
\end{tabular}

Regarding the overall model analysis, the $p$-value shows that the model can be defined as significant because the value is below 0.05, and a relationship between independent and dependent variables can be assumed, as shown in Tables 5 and 6. When checking the model fit, different R-square tests are performed by the system to assess how well the regression model explains the dependent variable. The pseudo R2 of Negelkerke can take values between 0 and 1 . The closer the value is to 1 , the better the regression. For the present research, the value of the Negelkerke R-square is 0.343 .

Table 5. Overall model test-Taiwan (Jamovi).

\begin{tabular}{ccc}
\hline Model & AIC & Nagelkerke R2 \\
\hline 1 (without nbstatus) & 1686 & 0.391 \\
2 (with nbstatus) & 1687 & 0.392 \\
\hline
\end{tabular}

Table 6. Assumption check-collinearity test.

\begin{tabular}{ccc}
\hline & VIF & Tolerance \\
\hline suskill & 1.19 & 0.841 \\
\hline UNEDUC97 & 1.04 & 0.957 \\
\hline fearfail & 1.05 & 0.951 \\
\hline opport & 1.14 & 0.875 \\
\hline knowent & 1.09 & 0.916 \\
\hline
\end{tabular}

The classification is shown by looking at the table below, which gives an overview of how much of the predicted values were correctly predicted by the system. It is visible that around $77 \%$ of the values were correctly classified, which can be considered as a better prediction than one that is done by accident, as shown in Table 7.

Table 7. Classification table-Taiwan (Jamovi).

\begin{tabular}{cccc}
\hline Accuracy & Specificity & Sensitivity & AUC \\
\hline 0.772 & 0.725 & 0.817 & 0.820 \\
\hline
\end{tabular}

The ROC curve of that model shows that it is not very close to the diagonal, and the area under the curve is around $80 \%$. It means that the model's fitness can be considered between the categories "acceptable" and "excellent." 
To analyze if Austria's results differ from Taiwan's results, the following paragraphs will summarize the empirical findings through Austria's logistic regression model.

The "chi-square" value and the " $p$-value" of each factor are shown in the figure below, and it is visible that the significance values of the Austrian model are similar to the values of the Taiwanese model, and the variable "nbstatus" can also be considered as not significant and has to be excluded from the model, as shown in Table 8.

Table 8. Omnibus likelihood ratio test to verify the significance of each variable-Austria (Illustration with Jamovi).

\begin{tabular}{ccc}
\hline Predictor & X2 & $p$ \\
\hline Suskill & 275.28 & $<0.001$ \\
fearfail & 92.39 & $<0.001$ \\
UNEDUC97 & 15.26 & $<0.001$ \\
nbstatus & 15.54 & $<0.001$ \\
knowent & 12.34 & $<0.001$ \\
opport & 1.94 & 0.164 \\
\hline
\end{tabular}

After reducing the model by removing the insignificant factor "opport," the regression coefficients of the independent variables are analyzed in order to be able to understand how the independent variables are affecting the number of female established businesses in Austria. As it is shown in the figure below, the variables "suskill," "knowent" and "UNEDUC97" and "nbstatus" are positively affecting the established business rate, and the variable "fearfail" is decreasing the number of established businesses when female entrepreneurs in Austria responded with "yes, as indicated in Table 9."

Table 9. Coefficients of the reduced model of Austria (Jamovi).

\begin{tabular}{ccc}
\hline Predictor & Estimate (B) & Odds Ratio \\
\hline suskill & 1.861 & 6.431 \\
\hline fearfail & -1.050 & 0.350 \\
\hline UNEDUC97 & 0.460 & 1.584 \\
\hline nbstatus & 0.498 & 1.646 \\
\hline knowent & 0.363 & 1.437 \\
\hline
\end{tabular}

Regarding the overall model analysis, the $p$-value shows that the model can be defined as significant because the value is below 0.05 , and a relationship between independent and dependent variables can be assumed, as shown in Tables 10 and 11.

Table 10. Overall model test Austria (Jamovi).

\begin{tabular}{ccc}
\hline Model & AIC & Nagelkerke R2 \\
\hline 1 (without opport) & 2107 & 0.338 \\
2 (with opport) & 2107 & 0.339 \\
\hline
\end{tabular}

Table 11. Assumption check-multicollinearity test Austria.

\begin{tabular}{ccc}
\hline & VIF & Tolerance \\
\hline suskill & 1.07 & 0.936 \\
fearfail & 1.03 & 0.966 \\
UNEDUC97 & 1.01 & 0.986 \\
nbstatus & 1.04 & 0.964 \\
knowent & 1.08 & 0.926 \\
\hline
\end{tabular}


The multicollinearity test shows that the variables are not strongly correlated because the VIF value is below 2.5.

Austria's overall model analysis shows that the model is significant with a very low $p$-value, and the Negelkerke R-square value is 0.338 .

Referring to the Austrian model's prediction, the accuracy score is around $71.6 \%$, and the area under the curve is $78.6 \%$. That means that the model fit is excellent, which could also be seen in the ROC curve, as shown in Table 12.

Table 12. Classification table-Austria (Jamovi).

\begin{tabular}{cccc}
\hline Accuracy & Specificity & Sensitivity & AUC \\
\hline 0.716 & 0.752 & 0.683 & 0.786 \\
\hline
\end{tabular}

To answer the following research question: "Which factors contribute significantly to female entrepreneurs' business success in the outperforming emerging market in Taiwan?", the following main findings were elaborated.

\subsection{Influence of the Educational Level}

According to the literature, most female entrepreneurs in Taiwan are educated in middle-level primary and secondary education [12]. After analyzing some descriptive statistics, it can be assumed that the literature assumption is correct because the educational level was mainly on the (upper) secondary education among the female participants.

Nevertheless, not enough evidence was found against the $\mathrm{H} 0$ hypotheses, and was not statistically significant, for the correlation between education level and business success. Therefore, H1 cannot be confirmed because no statistically significant evidence was found for the alternative hypothesis H1, and the following assumption could be made:

Hypotheses (H0). The factor "level of education" is not significantly correlated to business success among females in Taiwan, as shown in Figure 9.

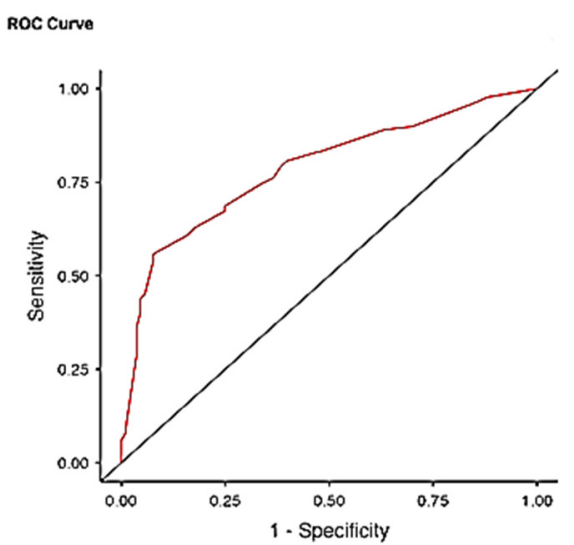

Figure 9. ROC analysis (Austria).

\subsection{Influence of Fear of Failure}

As mentioned in various articles and journals, fear of failure is a relevant factor in female entrepreneurship in Taiwan. It harms business success because women with a high degree of fear of failure do not have a high-risk propensity [31]. A significant correlation between fear of failure and business success was examined with the statistical test, and therefore, the alternative hypothesis $\mathrm{H} 1$ can be verified, and the $\mathrm{H} 0$ hypothesis can be rejected:

Hypotheses (H1). The factor "fear of failure" is significantly correlated to business success among females in Taiwan. 


\subsection{Influence of Personal Network}

As mentioned in the literature review, the probability of being an entrepreneur increases when people have an entrepreneurial network around them for the perception of the entrepreneurial skills because women are less confident concerning their skills than men [22].

According to the research findings of this paper, the following hypotheses can be accepted because $\mathrm{H} 0$ can be rejected since enough statistically significant evidence was given:

Hypotheses (H1). The factor "personal network" is significantly correlated to business success among females in Taiwan.

According to the statistical analysis and the statistical tests, it is evident that two out of three factors, which were chosen from the literature, do significantly contribute to the business success of female entrepreneurs. When it comes to the fear of failure, it can be assumed that the fear of failure of women will have a negative influence on the success of a business of female entrepreneurs in Taiwan, which means that the probability of owning an established business is getting reduced, when fear of failure exists. Furthermore, a female entrepreneur's network is also an essential and significant success factor of an established business because the number of participants who have connections to other business owners is positively related to the established business.

Nevertheless, it has to be noticed that some of the factors are influencing business success to a certain degree. However, it is not possible to predict the business success based on merely those factors, as it could be seen in the classification table, where only $62 \%$ of all values were predicted correctly and the "Negelkerke R2 value" has a relatively low value of 0.1040776 which means that the goodness of the model fit is medium. Nevertheless, it is more expressive than the Null-Model, where none of the mentioned predictors would be included.

\section{Conclusions}

This paper aims to analyze the relationship between various factors and a female entrepreneur's success by looking at the number of established businesses from the GEM database and how it is related to the success factors of educational level, personal network, and fear of failure. A logistic regression model was examined for testing the hypotheses, and the following statements can be drawn:

According to the literature, professional experience and education are essential success factors for entrepreneurship and have a massive influence on entrepreneurial skills development and the tendency to self-employment [29]. That assumption was not statistically significant because not all women can achieve such a high level of education in Taiwan and it is unusual to get a very high degree of education because it is costly. Furthermore, the literature often stated that females in Taiwan are doing their own business to realize themselves and differentiate from the stereotypes of who should be in the household and take care of the family. This is a rather personal decision, not necessarily connected to education level [30]. Nevertheless, entrepreneurial education shall be focused on various education stages because it is an excellent opportunity for females' self-fulfillment, strengthening self-confidence. It is even possible to have a successful business without a high degree of education, and that should be focused on because it is more about the willingness and the desire for self-realization [31]. This is also visible in the cultural dimensions of Hofstede, where Taiwan is considered a relatively "feminine" society, where people work for a living. It has to be noted that the results might change when the influence of the educational levels of only one age group is tested. Due to Taiwan's rapid development, it might be that the educational level of the younger generation who is owning an established business is much higher than it was 20 years ago [31].

When the expansion of the business is decided by women, factors like fear of failure and lack of awareness of own competencies often hinder that decision [31]. Of course, fear of failure is not only a barrier for female entrepreneurs. It is also something that could 
hinder male entrepreneurial success. Nevertheless, it has to be noticed that men are usually more self-confident and do not have so much pressure from society concerning childcare. The significant correlation between fear of failure and established businesses might be rooted in the cultural background. In Asian culture, it is expected that people do not want to "lose one's face." In this cultural context, this means that they are not risk-averse because they do not want to make mistakes, and they are not very self-confident when it comes to their skills because losing one's face means losing the reputation in that culture [19]. Furthermore, the highly scored cultural dimension, "Uncertainty Avoidance," of Taiwan also shows that this culture does not like uncomfortable or risky situations [16].

The importance of having a personal network connected with successful entrepreneurship was often underlined by theory, and the correlation can also be confirmed through that research. Informal networks for sharing information and resources among various enterprises in female-owned businesses are standard. This is also why women often prefer a leadership style based on teamwork [12]. It can also be justified with the cultural dimensions because Taiwan's culture is rather collectivist and not an individualist society, which means that people in Taiwan feel more comfortable in groups and take care of each other [16].

Several literature findings can reason the low accuracy score of the model. Many scientists believe that it is impossible to develop a conclusive theory that describes why some start-up projects fail, whereas other young companies succeed in growing in the long term [23]. A uniform understanding does not exist of how or by what the company's success is determined by, neither in the external nor internal success factor of research. Therefore, it is nearly impossible to find one formula for female entrepreneurs' business success [26].

This paper aimed to investigate how economic growth could be achieved by increasing the number of successful female entrepreneurs. After an extensive literature review of scientific articles and journals, connections to the hypotheses were built, and the authors tested them by using the GEM database. It was very challenging because the database was vast, and many variables were included, so it was challenging to identify precisely those variables needed for the research. The study subjects were the participants of the Adult Population Survey (APS) from the GEM database. To get the data only from the target group that should be focused on in this paper, the database was filtered to get only female participants from Taiwan, aged between 18 and 64. In total, the database includes 1098 observations of women in Taiwan and 117 interviews.

Nevertheless, after the whole data cleaning process, exciting findings were researched regarding female entrepreneurs' success factors in Taiwan. It can be concluded that $2 / 3$ of the factors, which were analyzed, had a statistically significant contribution to business success. The cultural dimensions of Hofstede of Taiwan were used to justify the findings. For female entrepreneurs' business success in Taiwan, it is essential to encourage them to grow and expand their business by taking away their fear of failure because having some risk propensity is essential for expanding the business.

Furthermore, women must get much support from their environment, like family, friends, and employees. Personal networks play an essential role in the development of skills among women. Therefore, it might also help to foster networking between various female entrepreneurs in Taiwan to exchange their entrepreneurial experiences and share their thoughts. This might increase their confidence and motivation. The level of education does not directly contribute to female business success in Taiwan, and this result might have cultural reasons. We would also encourage all female entrepreneurs to read this paper because it can help them understand the theory. After all, this might be reflected in their thoughts and feelings. If women know how to react to their needs and desires, solve some problems, and even know the reasons behind them, their awareness of their skills will increase. It will encourage and motivate them to keep doing their business and will support them in being successful. 
Nevertheless, it has to be noticed that many other influencing factors have to be considered when defining a thriving business among female entrepreneurs in Taiwan.

After reflecting on feminist liberal and social theories and the female awareness of entrepreneurial competencies, analyzing some success factors provides a better and more in-depth understanding of female entrepreneurship in Taiwan. These insights can be used for further research to compare those findings with other regions/countries.

Nevertheless, the research is limited to just a few factors, and a more detailed analysis of additional success factors, for example, access to financial resources or level of innovation, is recommended.

Author Contributions: L.-M.S. conducted the reasearch V.B. developed the concept and provided guidance, and T.H. checked all inputs and provided final version of the paper. All authors have read and agreed to the published version of the manuscript.

Funding: This research received no external funding.

Institutional Review Board Statement: Not applicable.

Informed Consent Statement: Not applicable.

Data Availability Statement: Data sharing not applicable. No new data were created or analyzed in this study.

Conflicts of Interest: The authors declare no conflict of interest.

\section{References}

1. Georgellis, Y.; Wall, H.J. Gender differences in self-employment. Int. Rev. Appl. Econ. 2005, 19, 321-342. [CrossRef]

2. Olarewaju, T.; Fernando, J. Gender Inequality and Female Entrepreneurship in Developing Countries. In Decent Work and Economic Growth; Filho, W.L., Azul, A.M., Brandli, L., Salvia, A.L., Wall, T., Eds.; Springer International Publishing: Berlin/Heidelberg, Germany, 2020; pp. 1-9. [CrossRef]

3. Elam, A.B.; Brush, C.G.; Greene, P.G.; Baumer, B.; Dean, M.; Harlow, R. Global Entrepreneurship Monitor 2018/2019 Women's Entrepreneurship Report; Wellesley: Cambridge, MD, USA, 2018.

4. Blanchflower, D. Self-Employment: More May Not Be Better; National Bureau of Economic Research: Cambridge, MA, USA, 2004; No. w10286. [CrossRef]

5. Cowling, M.; Taylor, M. Entrepreneurial Women and Men: Two Different Species? Small Bus. Econ. 2001, 16, 167-175. [CrossRef]

6. ChartsBin. Female Entrepreneurship Index. Available online: http://chartsbin.com/view/40538 (accessed on 17 December 2020).

7. Wang, S.-W. A Study of Women's Entrepreneurial Models in Taiwan. Available online: https://www.cier.edu.tw/public/Data/ 81269401871.pdf (accessed on 25 November 2020).

8. Kevane, M.; Wydick, B. Microenterprise Lending to Female Entrepreneurs: Sacrificing Economic Growth for Poverty Alleviation? World Dev. 2001, 29, 1225-1236. [CrossRef]

9. Terjesen, S.A. Conditions for high-potential female entrepreneurship. IZA World Labor 2016. [CrossRef]

10. Terjesen, S.; Lloyd, A. Female Entrepreneurship Index (2015), Global Entrepreneurship \& Development Index. 2015. Available online: https://www.researchgate.net/publication/280531562_Female_Entrepreneurship_Index_2015_Global_Entrepreneurship_ Development_Index (accessed on 25 November 2020). [CrossRef]

11. Lin, T.-L.; Lu, T.-Y.; Hsieh, M.-C.; Liu, H.-Y. From Conception to Start-Up: Who and What Affect Female Entrepreneurship. Contemp. Manag. Res. 2018, 14, 253-276. [CrossRef]

12. Sanyang, S.; Huang, W.-C. Small and Medium Enterprise for Women Entrepreneurs in Taiwan. World J. Agric. Sci. 2008, 4, 884-890.

13. Chuang, J.-H.; Wang, J.-H.; Liou, Y.-C.; Wang, S.-Y. Exploring Relationship between Personality, Creativity, and Entrepreneurship: Empirical Evidence from an Agricultural Students Survey in Taiwan. J. Adm. Bus. Stud. 2018, 4. [CrossRef]

14. Minniti, M. Female Entrepreneurship and Economic Activity. Eur. J. Dev. Res. 2010, 22, 294-312. [CrossRef]

15. Chen, W.; Weng, C.S.; Hsu, H. A study of the entrepreneurship of Taiwanese youth by the Chinese Entrepreneur Aptitude Scale. J. Technol. Manag. China 2010, 5, 26-39. [CrossRef]

16. Country Comparison. Hofstede Insights. 2020. Available online: https://www.hofstede-insights.com/country-comparison/ (accessed on 10 November 2020).

17. Thornton, P.H.; Ribeiro-Soriano, D.; Urbano, D. Socio-cultural factors and entrepreneurial activity: An overview. Int. Small Bus. J. Res. Entrep. 2011, 29, 105-118. [CrossRef]

18. Koellinger, P.; Minniti, M.; Schade, C. Gender Differences in Entrepreneurial Propensity: Gender and entrepreneurial propensity. Oxf. Bull. Econ. Stat. 2013, 75, 213-234. [CrossRef]

19. Kim, J.Y.; Nam, S.H. The Concept and Dynamics of Face: Implications for Organizational Behavior in Asia. Organ. Sci. 1998, 9 , 522-534. [CrossRef] 
20. Noguera, M.; Alvarez, C.; Urbano, D. Socio-cultural factors and female entrepreneurship. Int. Entrep. Manag. J. 2013,9 , $183-197$. [CrossRef]

21. Shane, S.; Venkataraman, S. The Promise of Entrepreneurship as a field of research. Acad. Manag. Rev. 2000, 25, 217. [CrossRef]

22. Chaston, I.; Scott, G.J. Entrepreneurship and open innovation in an emerging economy. Manag. Decis. 2012, 50, 1161-1177. [CrossRef]

23. Landström, H.; Harirchi, G.; Åström, F. Entrepreneurship: Exploring Knowledge Base. In Proceedings of the DIME Final Conference, Maastricht, The Netherlands, 6-8 April 2011.

24. Hansen, G.S.; Wernerfelt, B. Determinants of firm performance: The relative importance of economic and organizational factors. Strateg. Manag. J. 1989, 10, 399-411. [CrossRef]

25. Gartner, W.B. A Conceptual Framework for Describing the Phenomenon of New Venture Creation. Acad. Manag. Rev. 1985, 10, 696-706. [CrossRef]

26. Cooper, A.C.; Gimeno-Gascon, F.J.; Woo, C.Y. Initial human and financial capital as predictors of new venture performance. J. Bus. Ventur. 1994, 9, 371-395. [CrossRef]

27. Latham, J. Research Methods Framework. Available online: https://www.drjohnlatham.com/frameworks/research-methodsframework/ (accessed on 13 November 2020).

28. Helmenstine, A. What Is a Control Variable? Definition and Examples. Science Notes and Projects. Available online: https: / / sciencenotes.org/what-is-a-control-variable-definition-and-examples/ (accessed on 5 November 2020).

29. Fritsch, M. Entrepreneurship; Springer: Berlin/Heidelberg, Germany, 2016. [CrossRef]

30. Hu, M.-L.M.; Yuan, Y.-H. Constructing the Assessment Scale of Youth's Restaurant Entrepreneurship Competency: The Case of Taiwan. Sage Open 2020, 10, 2158244019900566. [CrossRef]

31. Rey-Martí, A.; Tur Porcar, A.; Mas-Tur, A. Linking female entrepreneurs' motivation for business survival. J. Bus. Res. 2015, 68, 810-814. [CrossRef]

32. Lo, K.-T.; Pan, J.-N.; Peng, S.-S. The role of gender and its potential channels to affect self-employment in Taiwan. Econ. Model. 2020, 89, 601-610. [CrossRef]

33. Bosma, N.; Kelley, D. Global Entrepreneurship Monitor 2018/2019 Global Report. 2019. Available online: https://www. gemconsortium.org/report/gem-2018-2019-global-report (accessed on 13 November 2020).

34. Olive, D.J. Multiple Linear Regression. In Linear Regression; Olive, D.J., Ed.; Springer International Publishing: Berlin/Heidelberg, Germany, 2017; pp. 17-83. [CrossRef]

35. He, W.; Baker, H.K. Small business financing: Survey evidence in West Texas. J. Entrep. Financ. 2007, 12, 27-54.

36. Afandi, E.; Kermani, M.; Mammadov, F. Social capital and entrepreneurial process. Int. Entrep. Manag. J. 2017, 13, 685-716. [CrossRef]

37. Abteilung Datenschutzrecht der UZH. Logistische Regressionsanalyse; Universität Zürich: Zürich, Switzerland, 2020. Available online: https://www.methodenberatung.uzh.ch/de/datenanalyse_spss/zusammenhaenge/lreg.html (accessed on 18 December 2020).

38. Al-Kwifi, O.S.; Tien Khoa, T.; Ongsakul, V.; Ahmed, Z.U. Determinants of female entrepreneurship success across Saudi Arabia. J. Transnatl. Manag. 2020, 25, 3-29. [CrossRef]

39. Fuller-Love, N. Female Entrepreneurship. In Entrepreneurship and Business; Galindo, M.-A., Guzman, J., Ribeiro, D., Eds.; Springer: Berlin/Heidelberg, Germany, 2008; pp. 291-308. [CrossRef]

40. Reavley, M.A.; Lituchy, T.R. Successful women entrepreneurs: A six-country analysis of self-reported determinants of success more than just dollars and cents. Int. J. Entrep. Small Bus. 2008, 5, 272. [CrossRef]

41. Liu, E.Y. The Effect of Oversampling and Undersampling on Classifying Imbalanced Text. Datasets; University of Texas: Austin, TX, USA, 2004. Available online: https: / / citeseerx.ist.psu.edu/viewdoc / download?doi=10.1.1.101.5878\&rep=rep1\&type=pdf $($ accessed on 13 November 2020). 